\title{
RANCANG BANGUN ALAT PERAGA GERAK HARMONIK SEDERHANA BERBASIS ARDUINO PADA SISTEM PEGAS
}

\author{
Marsofran Taneo, Infianto Boimau, Kostan D. F. Mataubenu \\ Program Studi Pendidikan Fisika, Sekolah Tinggi Keguruan dan Ilmu Pendidikan Soe \\ Email: infiantoboimau@gmail.com
}

Diterima: 21 Mei 2021. Direvisi: 23 Agustus 2021 Disetujui: 30 September 2021.

\begin{abstract}
Abstrak
Telah dilakukan rancang bangun alat peraga gerak harmonik sederhana berbasis arduino pada studi kasus sistem pegas. Alat peraga yang telah dikembangkan bertujuan untuk memvisualisasikan fenomena gerak harmonik sederhana dalam bentuk simpangan terhadap waktu, mengukur konstanta pegas, menyelidiki hubungan periode terhadap massa, dan frekuensi terhadap massa benda. Rancang bangun alat peraga dalam penelitian ini terdiri dari tiga bagian utama, yaitu perancangan perangkat keras (hardware), perancangan perangkat lunak (software) dan pengujian kinerja alat peraga yang dikembangkan. Rancang alat memanfaatkan sensor ultrasonik untuk mengukur simpangan benda. Pengukuran simpangan dan waktu disimpan pada komputer (PC) melalui komunikasi serial dengan bantuan PLX-DAQ. Hasil pengukuran konstanta pegas dengan menggunakan alat peraga yang dikembangkan adalah sebesar 5,21 N/m dengan kesalahan relatif 4,41\%. Hasil eksperimen juga menunjukan bahwa hubungan antara periode osilasi sebanding dengan akar kuadrat dari massa benda, sedangkan frekuensi osilasi sebanding dengan satu per akar kuadrat dari massa benda.
\end{abstract}

Kata Kunci: alat peraga, arduino, pegas, ultrasonik

\begin{abstract}
Arduino-based simple harmonic motion had been designed as teaching aids for spring system. The objective is to visualize the phenomena of simple harmonic motion in the form of time-distance, to measure spring constant, identify relationship of period and frequency toward mass. The design covers three prominent part, namely hardware design, software design, and test of the aids quality. The design also uses ultrasonic sensor to measure object distance. Distance and time measurement is saved in the PC through serial communication assisted with PLX-DAQ. Result of spring constant measurement using the developed aid reaches $5,21 \mathrm{~N} / \mathrm{m}$ with relative error is 4,41\%. The experiment result also shows that relation between period of oscillation equals root square of mass of object, and frequency of oscillation equals one per root square of mass of object.
\end{abstract}

Keywords: teaching aids, Arduino, spring, ultrasonic.

\section{PENDAHULUAN}

Getaran atau osilasi merupakan gerak bolak-balik suatu benda pada suatu lintasan yang memiliki suatu

posisi kesetimbangan. Gerak

harmonik sederhana mempunyai 
Taneo., Boimau., Mataubenu.- Rancang Bangun Alat Peraga ...

persamaan gerak dalam bentuk fisis (Boimau, Mellu \& Manuain, sinusoidal dan digunakan untuk 2020).

menganalisis suatu gerak periodik tertentu (Acu, Lapanporo, \&

Alat peraga adalah sarana Kushadiwijayanto, 2017). Gerak osilasi ini termasuk salah satu gejala fisis yang bersifat abstrak dan sulit dipahami dalam fisika sehingga didalam mempelajari tentang konsepkonsep yang bersifat abstrak / perlu dibuat menjadi lebih konkret atau nyata melalui kegiatan eksperimen praktikum (Nurlaeli \& Astuti, 2019).

Kegiatan praktikum dalam pembelajaran fisika sangat penting dalam mendukung pembelajaran dan memberikan penekanan pada aspek proses. Dengan demikian, pada aspek proses peserta didik diberi kesempatan untuk melakukan percobaan dan mengembangkan keterampilan seperti menggolongkan, mengamati, menafsirkan data mengukur, dan berkomunikasi (Gunawan, Harjono \& Sahidu, 2015). Salah satu faktor yang mempengaruhi keberhasilan kegiatan praktikum adalah penerapan alat peraga/ alat praktikum yang efektif dan efisien sehingga memudahkan peserta didik dalam mempelajari suatu fenomena

komunikasi dan interaksi antara guru dan peserta didik dalam proses pembelajaran. Pembelajaran dengan menggunakan alat peraga menjadi suatu rangkaian kegiatan untuk menyampaikan materi pelajaran yang bertujuan memberikan kesempatan kepada siswa untuk aktif belajar (Kause \& Boimau, 2019). Alat peraga yang dirancang merupakan alat peraga gerak harmonik sederhana pada kasus sistem pegas, berupa pegas yang digantung pada penyangga dan diberi beban. Alat peraga ini dirancang untuk membantu guru dalam menyajikan materi gerak harmonik sederhana, yang mana alat peraga ini dapat memvisualisasikan fenomena tentang gerak harmonik sederhana.

Perkembangan ilmu pengetahuan dan teknologi telah menghasilkan berbagai perangkat elektronik yang dapat dimanfaatkan dalam pengembangan alat peraga digital dengan akurasi dan presisi yang tinggi. Salah satu perangkat elektronik berbiaya murah namun 
Taneo., Boimau., Mataubenu.- Rancang Bangun Alat Peraga ...

memiliki unjuk kerja tinggi sebagai kendali dalam pengembangan alat peraga fisika adalah arduino (Sari, 2019). Arduino memiliki sejumlah fitur handal yang dapat di-interfacekan dengan berbagai device lain seperti sensor, aktuator dan Liquid Crystal Display (LCD). Arduino dilengkapi dengan beberapa fitur penting seperti Input/Output digital, input analog, Analog to Digital Converter (ADC), timer, counter, Pulse Width Modulation (PWM), interupt dan komunikasi serial (Sauri, 2017).

Sensor ultrasonik adalah sensor yang bekerja berdasarkan prinsip kerja pantulan suara, dimana sensor menghasilkan gelombang suara yang kemudian menangkap kembali dengan perbedaan waktu sebagai dasar pengindra. Frekuensi kerja sensor ultrasonik pada daerah diatas gelombang suara lebih dari $20 \mathrm{kHz}$ (Dilfa, Salahhudin \& Basyir, 2019). Sensor ultrasonik telah memiliki aplikasi yang luas dalam mengembangkan berbagai alat peraga fisika seperti pengukur jarak atau ketinggian dari suatu objek yang statis maupun dinamis (Kause \& Boimau, 2019).

Alat peraga fisika berbasis arduino telah banyak dikembangkan dengan memanfaatkan berbagai sensor sebagai input sesuai dengan besaran fisika yang diukur. Beberapa penelitian yang memanfaatkan arduino dan sensor sebagai device utama dalam mengembangkan alat peraga fisika, antara lain: alat peraga gerak jatuh bebas untuk mengukur percepatan gravitasi bumi (Qomariyah \& Wirawan, 2018), alat peraga rotasi benda tegar pada bidang miring untuk mengukur kostanta momen inersia (Boimau \& Mellu, 2019), alat peraga lampu sensor (Permatasari, Yuberti \& Anggraini, 2019), alat ukur laju bunyi di udara (Boimau, Irwanto \& Taneo, 2019), alat praktikum viskometer untuk mengukur kekentalan fluida (Tissos, Yulkifli \& Kamus, 2014), alat peraga polarisasi cahaya (Mataubenu \& Langtang, 2018), dan alat peraga kalor untuk mengukur konstanta Joule (Mataubenu, 2018).

Arduino dapat di-interface-kan dengan komputer untuk akuisisi dan pengolahan data yang lebih kompleks 
Taneo., Boimau., Mataubenu.- Rancang Bangun Alat Peraga ...

dengan memanfaatkan fitur yang diperlukan untuk satu kali komunikasi serial. Salah satu getaran atau satu siklus. Frekuensi software yang mampu mendukung getaran $(f)$ adalah banyaknya getaran akuisisi data dari arduino ke untuk satu satuan waktu. Hubungan komputer adalah PLX-DAQ. PLX- antara periode dan frekuensi DAQ (Parallax Data Aqusitions) dinyatakan oleh persamaan (1).

adalah add-on dari data akusisi mikrokontroler parallax untuk Microsoft Excel. Arduino yang dihubungkan ke sensor dan port PC dapat mengirim data secara otomatis ke Excel. PLX-DAQ digunakan untuk komunikasi antara ardino dan Microsoft Excel yang kemudian dapat diolah untuk dianalisa dalam bentuk grafik (Fachri, Sara \& Away, 2015).

\section{GERAK OSILASI PEGAS}

Gerak harmonik sederhana (GHS) adalah gerak bolak-balik benda melalui suatu titik kesetimbangan tertentu dengan banyaknya getaran benda dalam setiap sekon selalu konstan. Karakteristik penting dari gerak osilasi adalah amplitudo, periode, frekuensi dan frekuensi sudut. Amplitudo getaran (A) merupakan besar perpindahan maksimum dari titik kesetimbangan. Periode getaran $(T)$ merupakan waktu

$$
T=\frac{1}{f}
$$

Pegas merupakan salah satu bahan elastis yang dapat diuji sifat-sifat osilasinya dengan menggantungkan sebuah benda bermassa $m$ seperti pada Gambar 1. Apabila benda tersebut disimpangkan sejauh $y$ lalu dilepas, maka akan terjadi gerak harmonik sederhana. Pada kasus ini akan berlaku hukum Hooke yang menjelaskan bahwa: gerak yang dilakukan oleh suatu partikel bermassa $m$ karena pengaruh suatu gaya yang sebanding dengan perpindahan partikel tersebut, tetapi berlawanan tandanya. Penyebab benda bergetar adalah karena adanya gaya pemulih yang bekerja pada benda tersebut. Ketika gaya pemulih berbanding lurus dengan simpangan dari titik kesetimbangan, getaran yang terjadi disebut gerak harmonik sederhana (Giancoli, 2014). 


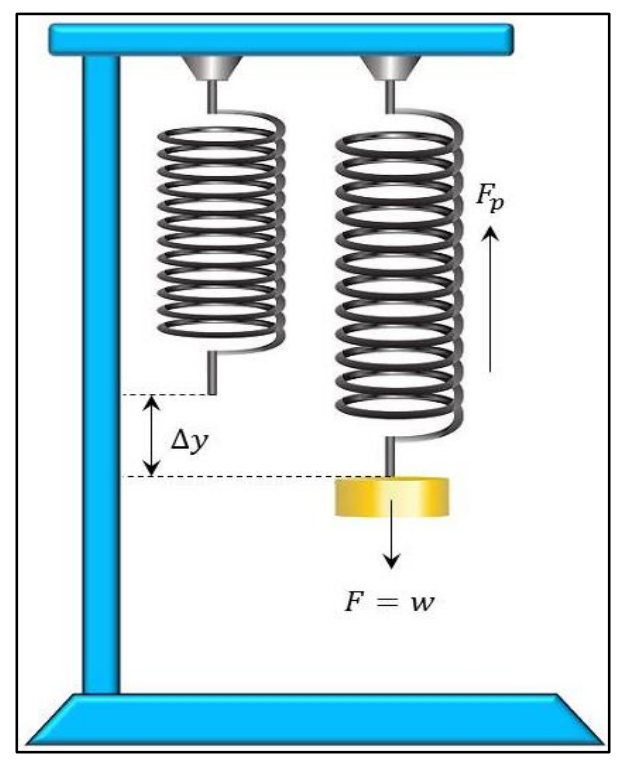

Gambar 1. Sistem Pegas Pada Gerak Osilasi

Secara umum, gaya pemulih sebanding dengan simpangan jika simpangannya cukup kecil. Secara matematis, Hukum Hooke dapat dituliskan:

$$
F_{p}=-k \Delta y
$$

dimana $F_{p}$ merupakan gaya pemulih $(N), k$ adalah konstanta pegas $(N / m)$, dan $\Delta y$ adalah perubahan panjang pegas $(m)$. Tanda $(-)$ menunjukkan bahwa arah gaya pemulih berlawanan arah dengan arah simpangan benda. Persamaan gerak harmonik sederhana pada sistem pegas dituliskan pada persamaan (3):

$$
y=A \sin \left(\omega t+\varphi_{0}\right)
$$
amplitude $(m), \omega$ adalah frekuensi sudut $(\mathrm{rad} / \mathrm{s}), t$ adalah waktu osilasi (s) dan $\varphi_{0}$ adalah fase awal (rad). Sedangkan frekuensi sudut, periode dan frekuensi gerak harmonik sederhana sistem pegas dituliskan oleh persamaan (4), (5) dan (6):

$$
\begin{aligned}
\omega & =2 \pi f=\frac{2 \pi}{T} \\
T & =2 \pi \sqrt{\frac{m}{k}} \\
f & =\frac{1}{2 \pi} \sqrt{\frac{k}{m}}
\end{aligned}
$$

dimana $m$ adalah massa benda. Nilai konstanta pegas dapat ditentukan menggunakan persamaan (5) menjadi:

$$
k=\frac{4 \pi^{2} m}{T^{2}}
$$

dengan $y$ adalah simpangan $(m), A$ adalah simpangan maksimum atau 
Taneo., Boimau., Mataubenu.- Rancang Bangun Alat Peraga ...

\section{METODE}

Perancangan alat peraga gerak harmonik sederhana berbasis arduino yang dikembangkan dalam penelitian ini dibagi tiga tahap yaitu: perancangan perangkat keras (hardware), perancangan perangkat lunak (software), dan pengujian kinerja alat peraga. Perancangan perangkat keras alat peraga terdiri dari komponen input, proses dan output. Komponen input sistem perangkat keras terdiri dari sensor ultrasonik dan tombol push button. Komponen pemrosesan data berupa arduino dan komponen sistem output perangkat keras berupa Liquid Crystal Display (LCD). Disamping itu, catu daya dirancang untuk menyuplai arus bagi semua perangkat elektronik. Diagram komponen perangkat keras alat peraga yang dikembangakan ditunjukan pada Gambar 2.

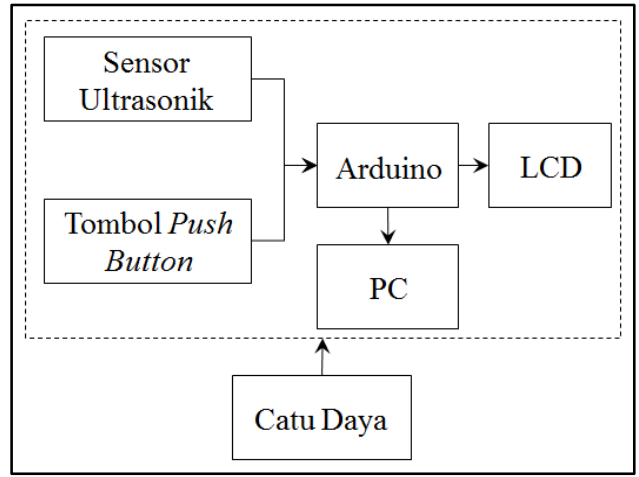

Gambar 2. Diagram perangkat keras (hardware)

Komponen perangkat keras untuk mengulang pengukuran kerja (hardware) yang ditunjukan pada alat peraga. Dengan demikian, data Gambar 2 menunjukan sensor input dari sensor ultrasonik dan ultrasonik dan tombol push button tombol push button akan diproses digunakan sebagai perangkat input oleh arduino sebagai hasil untuk arduino. Push button berfungsi sebagai tombol input untuk kendali kerja alat peraga. Tombol "start" berfungsi untuk memulai pengukuran sedangkan tombol "reset" berfungsi pengukuran simpangan dan waktu. Waktu tempuh pegas berosilasi akan dicacah menggunakan timer pada arduino. Hasil pencacahan simpangan dan waktu akan ditampilkan pada 
Taneo., Boimau., Mataubenu.- Rancang Bangun Alat Peraga ...

LCD agar dapat dibaca dengan mudah oleh pengguna. Data simpangan benda juga dikirimkan secara serial ke komputer agar dapat disimpan dalam bentuk tabel pada Microsoft Excel.

Perancangan perangkat lunak (sotware) alat peraga menggunakan bahasa pemograman C\#. Perangkat lunak alat peraga dikembangkan dengan memanfaatkan compiler Integrated Development Environment (IDE) arduino dan terdiri dari beberapa blok utama yaitu deklarasi pustaka, variabel, definisi pin-pin arduino, setup pin-pin arduino dan LCD, pembuatan fungsi timer, mengukur simpangan terhadap waktu dan menuliskan hasil pengukuran pada LCD. Program aplikasi PLXDAQ terdiri atas tiga bagian utama, yaitu: posisi port, control dan baudrate COM. Data yang diolah kemudian ditampilkan pada komputer melalui komunikasi serial dengan bantuan PLX-DAQ yang ditampilkan dalam bentuk grafik.

Pengujian ini dilakukan untuk mengetahui setiap komponen atau bagian-bagian yang digunakan apakah alat ini dapat bekerja dengan baik atau tidak. Pengujian sistem meliputi pengujian terhadap perangkat mekanik alat peraga yang berfungsi sebagai media untuk memperagakan gerak harmonik sederhana pada pegas. Perancangan mekanik alat peraga terdiri dari beberapa komponen utama yaitu penyangga, kotak sensor ultrasonik, pegas, massa (beban) yang bervariasi ukurannya, dan kotak elektronik. Dalam perancangan mekanik alat peraga, tempat kedudukan pegas dan sensor ultrasonik didesain agar dapat dilakukan pengukuran dan dilengkapi pula dengan penyangga yang berfungsi sebagai tempat penopang pegas. Pengujian rangkaian elektronik alat peraga gerak harmonik sederhana digital terdiri dari pengujian sensor ultrasonik, pengujian arduino, pengujian power suply, dan pengujian LCD. Perangkat rangkaian elektronik alat peraga akan diuji kelayakannya yang digunakan untuk menganalisis konsep gerak harmonik sederhana pada pegas.

\section{HASIL DAN PEMBAHASAN}

Hasil rancang alat peraga fisika pada kasus gerak harmonik sederhana 
Taneo., Boimau., Mataubenu.- Rancang Bangun Alat Peraga ...

berbasis arduino yang dikembangkan harmonik sederhana. Hasil desain alat pada penelitian ini, dapat digunakan peraga gerak harmonik sederhana secara efektif untuk melakukan ditunjukan pada Gambar 3. analisis terhadap konsep gerak

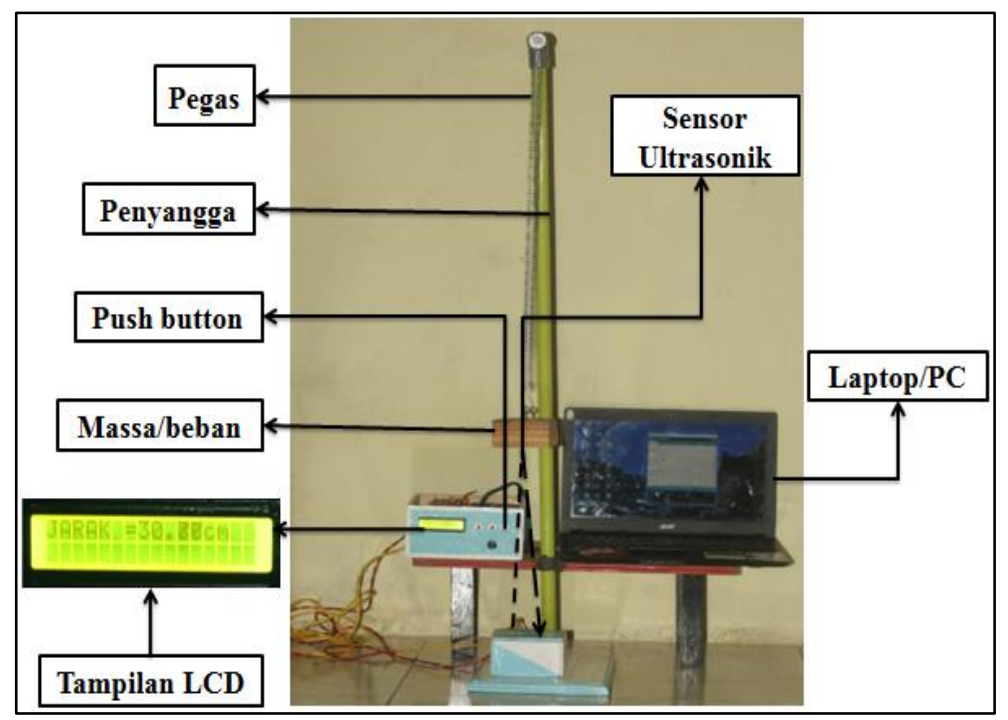

Gambar 3. Hasil rancang bangun alat peraga GHS pada sistem pegas

Prinsip kerja alat peraga yaitu mengukur simpangan sistem pegas menggunakan sensor ultrasonik yang dikendalikan melalui tombol push button, mengukur waktu tempuh pegas berosilasi menggunakan timer arduino yang dikendalikan oleh trigger sensor ultrasonik, data pengkuran simpangan dan waktu disimpan pada komputer (PC) melalui komunikasi serial dengan bantuan PLX-DAQ dan hasil pengukuran ditampilkan pada LCD berupa simpangan pegas.
Hasil desain perangkat keras terdiri dari empat komponen utama, yaitu: sensor ultrasonik, arduino, tombol push button, dan LCD. Sensor ultrasonik memiliki empat buah pin yang masing-masing pinnya memiliki fungsi yang berbeda. Pin Vcc sebagai pin input tegangan untuk menyediakan arus bagi sensor. Pin trigger berfungsi sebagai pemancar gelombang ultrasonik yang dihubungkan ke pin input digital 3. Pin echo berfungsi sebagai penerima pantulan gelombang ultasonik yang dihubungkan ke pin input digital 
arduino 4. Pin ground berfungsi ultrasonik serta mengendalikan sebagai grounding pada rangkaian pengukuran waktu rambat gelombang elektronik. Pin trigger dan pin echo dari transmitter sampai receiver sensor ultrasonik digunakan sebagai setelah dipantulkan oleh objek yang pin I/O dalam mengendalikan akan diukur jaraknya. maupun membangkitkan gelombang

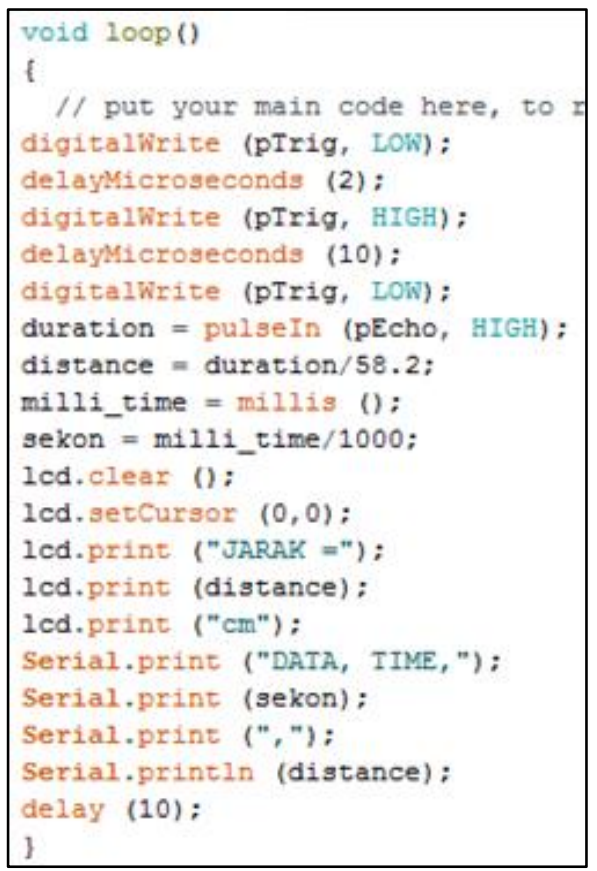

Gambar 4. Hasil perancangan perangkat lunak

Hasil rancangan perangkat lunak alat peraga dalam menghitung simpangan pegas terhadap waktu dapat ditunjukan pada Gambar 4. Desain perangkat lunak yang dikembangkan dalam penelitian ini berfungsi untuk mengatur kinerja alat peraga berdasarkan alur tertentu. Desain perangkat lunak yang dikembangkan terdiri dari deklarasi pin-pin arduino, pembuatan fungsi timer, mengukur jarak, mengirimkan data cacahan simpangan ke komputer secara serial dan menuliskan hasil pengukuran pada LCD.

Pengujian alat peraga dilakukan dengan mengukur simpangan benda dan waktu osilasi. Hasil pengukuran alat peraga disimpan pada komputer melalui komunikasi serial dengan bantuan PLX-DAQ, selanjutnya dianalisis menggunakan persamaan 
Taneo., Boimau., Mataubenu.- Rancang Bangun Alat Peraga ...

umum gerak harmonik sederhana pegas. Hasil pengujian alat peraga pada persamaan (4). Analisis untuk massa benda sebesar $100 \mathrm{gr}$ dilakukan untuk menentukan nilai frekuensi sudut $(\omega)$ yang selanjutnya yang telah dianalisis mengunakan dipakai untuk menentukan frekuensi teknik interpolasi data ditunjukkan osilasi, periode osilasi, dan konstanta pada Gambar 5.

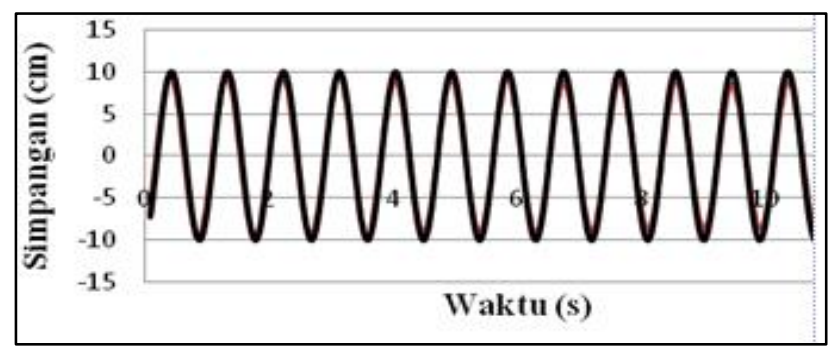

Gambar 5. Grafik hasil interpolasi data simpangan terhadap waktu

Hasil interpolasi data yang disajikan pada Gambar 5 diperoleh persamaan simpangan terhadap waktu adalah $y=9,9 \sin (6,96 t-1)$, dimana $y$ dalam $\mathrm{cm}$ dan $t$ dalam $s$. Persamaan simpangan yang diperoleh menunjukkan nilai amplitudo sebesar $9,9 \mathrm{~cm}$, nilai frekuensi sudut osilasi sebesar 6,96 rad/s, dan nilai fase awal adalah -1 rad. Nilai frekuensi sudut yang diperoleh digunakan untuk menentukan periode dan frekuensi osilasi menggunakan persamaan (4). Sedangkan nilai konstanta elastisitas pegas ditentukan menggunakan persamaan (7) setelah nilai periode dihitung. Hasil pengujian dan analisis pengujian kinerja alat peraga terhadap variasi massa benda dalam penelitian ini ditunjukkan pada Tabel 1.

Rerata nilai konstanta yang diperoleh menggunakan alat peraga yang dirancang adalah $5,21 \mathrm{~N} / \mathrm{m}$ dengan standar deviasi sebesar 0,23 dan kesalahan relatif pengukuran sebesar 4,41\% . Hasil pengukuran yang diperoleh memiliki persentase kesalahan sebesar 4,93\% jika dibandingkan dengan nilai teoritik konstanta pegas sebesar 5,48 N/m. Hasil pengukuran konstanta elastisitas pegas menggunakan alat peraga memiliki keakuratan yang tidak jauh berbeda dengan hasil penelitian yang yang dilakukan oleh Yulkifli, Yohandri, dan Hatthoahira (2017) 
Taneo., Boimau., Mataubenu.- Rancang Bangun Alat Peraga ...

dalam mengukuran konstanta kesalahan sebesar 3,69\%.

elastisitas pegas dengan persentase

Tabel 1. Hasil pengujian alat peraga terhadap variasi massa benda

\begin{tabular}{ccccc}
\hline $\begin{array}{c}\text { Massa } \\
(\boldsymbol{k g})\end{array}$ & $\begin{array}{c}\text { Frekuensi Sudut } \\
(\boldsymbol{r a d} / \boldsymbol{s})\end{array}$ & $\begin{array}{c}\text { Periode } \\
(\boldsymbol{s})\end{array}$ & $\begin{array}{c}\text { Frekuensi } \\
(\boldsymbol{H z})\end{array}$ & $\begin{array}{c}\text { Konstanta Pegas } \\
(\boldsymbol{N} / \boldsymbol{m})\end{array}$ \\
\hline 0,100 & 6,97 & 0,86 & 1,147 & 4,86 \\
0,125 & 6,29 & 0,95 & 1,026 & 4,95 \\
0,150 & 6,14 & 1,05 & 0,936 & 5,65 \\
0,175 & 5,41 & 1,14 & 0,866 & 5,12 \\
0,200 & 5,13 & 1,22 & 0,811 & 5,26 \\
0,225 & 4,82 & 1,30 & 0,765 & 5,23 \\
0,250 & 4,58 & 1,36 & 0,725 & 5,24 \\
0,275 & 4,39 & 1,43 & 0,691 & 5,30 \\
0,300 & 4,21 & 1,49 & 0,662 & 5,32 \\
\hline
\end{tabular}

Data hasil penelitian yang ini sesuai dengan analisis teoritik ditunjukkan pada Tabel 1 dapat seperti pada persamaan (5), bahwa dianalisis dalam bentuk grafik untuk $T \approx \sqrt{m}$. Sedangkan nilai koefisien menentukan pengaruh variasi massa benda terhadap periode osilasi seperti yang ditunjukkan pada Gambar 6. Gambar 6 memperlihatkan grafik hubungan periode osilasi dan massa benda adalah $y=2,754 x^{0,5075}$, dimana $y$ adalah periode osilasi dan $x$ adalah massa benda. Persamaan hasil regresi yang diperoleh menunjukkan bahwa periode osilasi sebanding dengan akar dari massa benda. Hasil 2,754 menunjukkan suku $2 \pi / \sqrt{k}$ sehingga nilai konstanta elastisitas pegas dapat ditentukan menggunakan persamaan $k=(2 \pi / 2,754)^{2}=5,2$ $\mathrm{N} / \mathrm{m}$. Nilai ini sama dengan retata konstanta elastisitas pegas yang diperoleh pada Tabel 1, yaitu $5,21 \mathrm{~N} / \mathrm{m}$.

Frekuensi osilasi dan massa benda pada Tabel 1 dapat pula dianalisis secara regresi untuk menentukan 
Taneo., Boimau., Mataubenu.- Rancang Bangun Alat Peraga ...

hubungan kedua variabel seperti ditunjukkan pada Gambar 7. Grafik ini memperlihatkan hubungan frekuensi osilasi dan massa benda adalah $y=0,3624 x^{-0.5}$ dimana $y$ adalah frekuensi osilasi dan $x$ adalah massa benda. Persamaan yang diperoleh menunjukkan bahwa frekuensi osilasi sebanding dengan satu per akar massa benda. Hasil ini

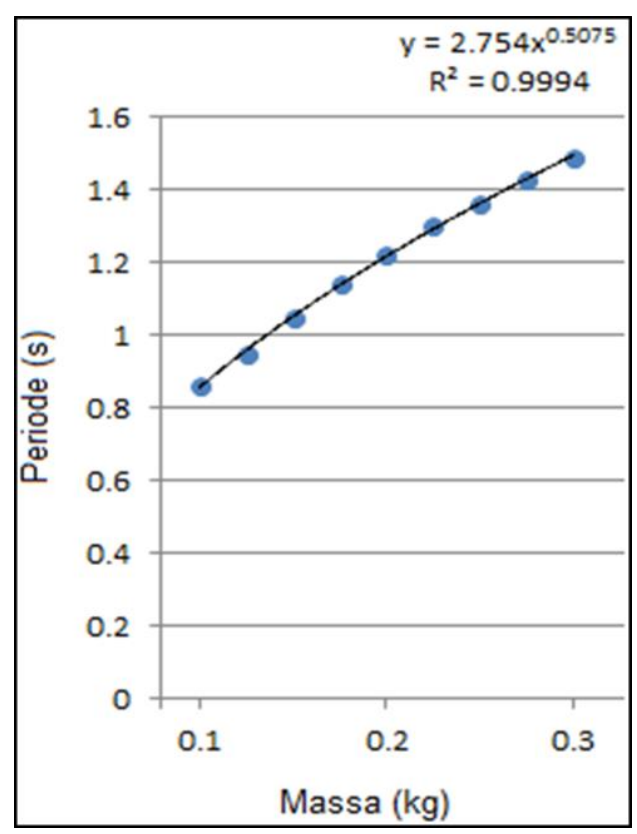

Gambar 6. Grafik Pengaruh Massa Benda Terhadap Periode Osilasi sesuai dengan analisis teoritik seperti diperlihatkan dalam persamaan (6) bahwa $f \approx 1 / \sqrt{m}$. Sedangkan nilai koefisien 0,3624 menunjukkan suku $\sqrt{k} / 2 \pi$ sehingga konstanta pegas ditentukan menggunakan persamaan $k=((2 \pi)(0,3624))^{2}=5,18 \mathrm{~N} / \mathrm{m}$. Nilai ini memiliki kesalahan relatif sebesar $0,58 \%$ terhadap nilai rerata $k$ yang diperoleh, yaitu $5,21 \mathrm{~N} / \mathrm{m}$.

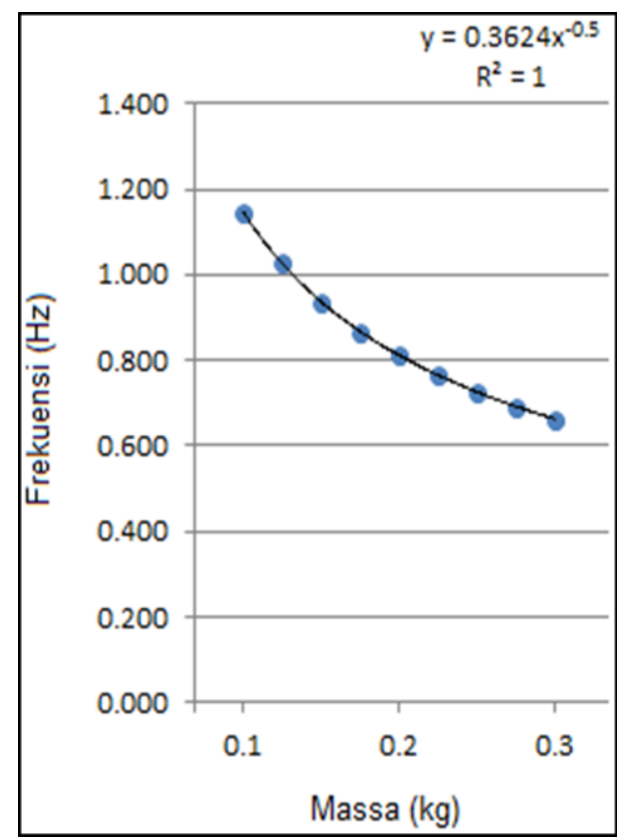

Gambar 7. Grafik Pengaruh Massa Terhadap Frekuensi

periode dan $x$ adalah frekuensi. Apabila persamaan yang diperolwh dibulatkan maka dapat ditulis menjadi $y=x^{-1}$ atau $y=\frac{1}{x}$. Hasil ini menunjukkan bahwa periode osilasi 
Taneo., Boimau., Mataubenu.- Rancang Bangun Alat Peraga ...

sebanding dengan satu per frekuensi atau sebaliknya frekuensi osilasi sebanding dengan satu per periode osilasi. Hasil analisis yang diperoleh sesuai dengan analisis teoritik yang ditunjukkan pada persamaan (1).

Analisis regresi pengaruh massa benda terhadap frekuensi sudut ditunjukkan pada Gambar 9. Analisis regresi yang dilakukan menunjukkan bahwa pengaruh massa benda

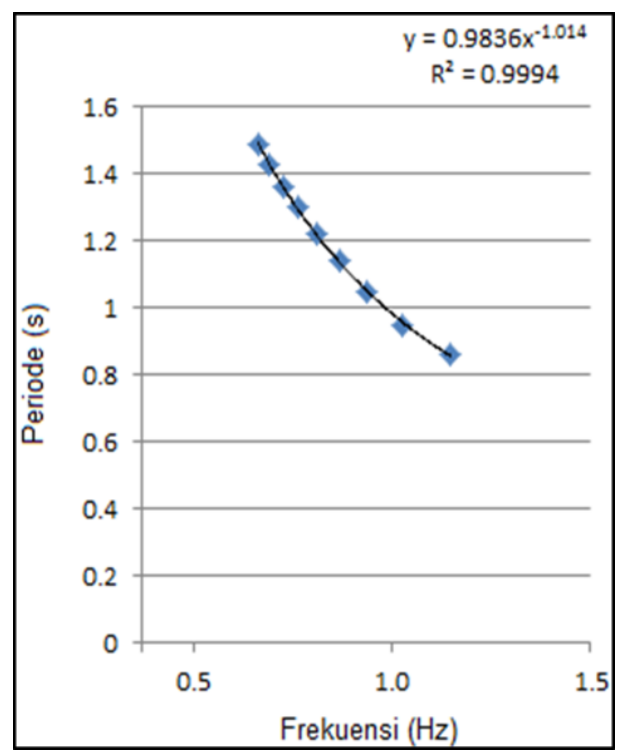

Gambar 8. Analisis regresi frekuensi terhadap periode osislasi

\section{KESIMPULAN}

Alat peraga gerak harmonik sederhana studi kasus pada pegas telah dikembangkan menggunakan perangkat keras seperti sensor terhadap frekuensi sudut dinyatakan dalam bentuk persamaan $y=$ $2,4017 x^{-0,469}$ dimana $y$ adalah frekunesi sudut dan $x$ adalah massa benda. Persamaan ini menunjukkan bahwa frekuensi sudut sebanding dengan satu per akar massa benda atau $\omega \approx 1 / \sqrt{m}$. Hasil ini sesuai dengan analisis teoritik yang ditunjukkan oleh persamaan $\omega=$ $\sqrt{k / m}$.

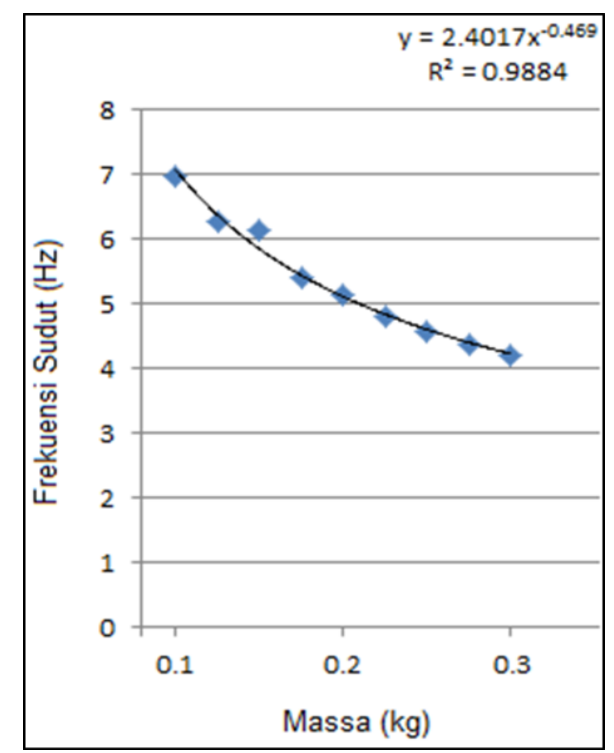

Gambar 9. Grafik pengaruh massa benda terhadap frekuensi sudut

ultasonik, tombol push button, arduino, penampil LCD dan komputer, sedangkan perangkat lunak menggunakan bahasa $\mathrm{C \#}$ dan program aplikasi PLX-DAQ. Hasil pengukuran 
Taneo., Boimau., Mataubenu.- Rancang Bangun Alat Peraga ...

osilasi pegas dengan bantuan PLX-

DAQ didapatkan konstanta pegas sebesar 5,21 N/m dengan standar deviasi 0,23 dan persentase kesalahan relatif sebesar $4,41 \%$.

Hasil Analisis data eksperimen menggunakan regresi menunjukan bahwa hubungan antara periode osilasi sebanding dengan akar kuadrat dari massa benda, frekuensi osilasi sebanding dengan satu per akar kuadrat dari massa benda, periode osilasi sebanding dengan satu per frekuensi osilasi dan frekuensi sudut sebanding dengan satu per akar massa benda.

\section{DAFTAR PUSTAKA}

Acu, Y., Lapanporo, P. B., Kushadiwijayanto, A. A. (2017). Model Sederhana Gerak Osilator dengan Massa Berubah Terhadap Waktu Menggunakan Metode Rungge Kutta. POSITRON, 7 (2): 42-47.

Boimau, I., Mellu, N. K. R., Manuain, R. M. (2020). Rancang Bangun Alat Praktikum Viskometer Berbasis Ardiono. Wahana Fisika, 5(1): 28-40.

Boimau, I., Mellu, N. K. R. (2019). Investigation to Inertial Constant of Rotating Object on a Slope Based on Arduino. International of Innovative Science and Research Technology, 4(2): 442-446.
Boimau, I., Irwanto, R., Taneo, M. (2019). Rancang Bangun Alat Ukur Laju Bunyi Di Udara Menggunakan Sensor Ultrasonik Berbasis Arduino. Cyclotron, 2(2): 1-6.

Dilfa, H., Salahhudin,, Basyir, M. (2019). Rancang Bangun Sistem Monitoring Dan Kontrol Buka Tutup Waduk Lhoksemauwe Secara Otomatis Berbasis Android. Proceeding Seminar Nasional, 3(1): 203.

Fachri, M. R., Sara, I. D., Away, Y. (2015). Pemantauan Parameter Panel Surya Berbasis Arduiono Secara Real Time. Jurnal Rekayasa Elektrika, 11(4): 123128.

Giancoli, D. C. (2014). Fisika (Prinsip dan Aplikasi), $7^{\text {th }}$ ed., Jakarta: Penerbit Erlangga.

Gunawan., Harjono, A., Sahidu, H. (2015). Pengembangan Model Laboratorium Virtual Berorientasi Pada Kemampuan Pemecahan Masalah Bagi Calon Guru Fisika. Jurnal Materi dan Pembelajaran Fisika, 5(2): 41-46.

Kause, M., Boimau, I. (2019). Rancang Bangun Alat Peraga Fisika Berbasis Arduino (Studi Kasus Gerak Jatuh Bebas). Cyclotron, 2(1): 13-19.

Mataubenu, K. D. F. (2018). Development of a Simple Heat Learning Media to Enhance Student Science Process Skill. International Journal of Science and Research. 7(5): 1698-1703.

Mataubenu, K. D. F., Langtang, D. (2018). Development of Light Polarization Learning Tool Based 
Taneo., Boimau., Mataubenu.- Rancang Bangun Alat Peraga ...

on Arduino and Scientific

Performance. International

Journal of Science and Research. 7(12): 156-160.

Nurlaeli., Astuti, I. (2019). Media Analisis Osilator Pada Pegas Berbasis Graphic User Interface. Jurnal Pendidikan Fisika UM Metro, 7 (2): 245-255.

Permatasari, A., Yuberti., Anggraini, W. (2019). Pengembangan Lampu Sensor Berbasis Arduino Uno Sebagai Alat Perga Fisika. Indinesian Journal Of Science and Mathematics Education, 2(3): 380387.

Qomariyah, N., Wirawan, R. (2018). Aplikasi Sensor Infrared dan Arduino Untuk Alat Peraga Sederhana Gerak Jatuh Bebas. Prosiding PKM-CSR, 1: 652-659.

Sari, U. (2019). Using the Arduino for the Experimental
Determination of a Friction Coefficient by Movement on an Incline Plane. Phys. Educ. 54: 1-7.

Sauri, M. (2017). Pemanfaatan Arduino Nano Dalam Perancangan Media Pembelajaran Fisika. Natural Science Journal, 3(1): 474-480.

Tissos, N. P., Yulkifli., Kamus, Z. (2014). Pembuatan Sistem Pengukuran Viskositas Fluida Secara digital Menggunakan Sensor Efek Hall UGN3503 Berbasis Arduino Uno328. Jurnal Saintek, 6(1): 71-81.

Yulkifli., Yohandra., Hatthoahira. (2017). Rancang Bangun Set Eksperimen Gerak Harmonik Sederhana Menggunakan Sensor PING dan Photodioda Berbasis Mikrokontroller. Jurnal Aplikasi Fisika, 13(3): 82-83. 